\title{
The impact of severe traumatic brain injury on a novel base deficit- based classification of hypovolemic shock
}

Manuel Mutschler ${ }^{1,2^{*}}$, Ulrike Nienaber ${ }^{3}$, Arasch Wafaisade ${ }^{1}$, Thomas Brockamp ${ }^{1}$, Christian Probst ${ }^{1}$, Thomas Paffrath $^{1}$, Bertil Bouillon ${ }^{1}$, Marc Maegele ${ }^{1}$ and the TraumaRegister DGU ${ }^{\circledR}$

\begin{abstract}
Background: Recently, our group has proposed a new classification of hypovolemic shock based on the physiological shock marker base deficit (BD). The classification consists of four groups of worsening BD and correlates with the extent of hypovolemic shock in severely injured patients. The aim of this study was to test the applicability of our recently proposed classification of hypovolemic shock in the context of severe traumatic brain injury (TBI).

Methods: Between 2002 and 2011, patients $\geq 16$ years in age with an AlS head $\geq 3$ have been retrieved from the German TraumaRegister DGU ${ }^{\circledR}$ database. Patients were classified into four strata of worsening BD [(class I (BD $\left.\leq 2 \mathrm{mmol} / \mathrm{l}\right)$, class $\|$ (BD > 2.0 to $6.0 \mathrm{mmol} / \mathrm{l})$, class III (BD > 6.0 to $10 \mathrm{mmol} / \mathrm{l})$ and class IV $(\mathrm{BD}>10 \mathrm{mmol} / \mathrm{l})$ ) and assessed for demographic and injury characteristics as well as blood product transfusions and outcomes. The cohort of severely injured patients with TBI was compared to a population of all trauma patients to assess possible differences in the applicability of the BD based classification of hypovolemic shock.

Results: From a total of 23,496 patients, 10,201 multiply injured patients with TBI (AIS head $_{2} \geq 3$ ) could be identified. With worsening of $\mathrm{BD}$, a consecutive increase of mortality rate from $15.9 \%$ in class I to $61.4 \%$ in class IV patients was observed. Simultaneously, injury severity scores increased from $20.8( \pm 11.9)$ to $41.6( \pm 17)$. Increments in BD paralleled decreasing hemoglobin, platelet counts and Quick's values. The number of blood units transfused correlated with worsening of BD. Massive transfusion rates increased from $5 \%$ in class I to $47 \%$ in class IV. Between multiply injured patients with TBI and all trauma patients, no clinically relevant differences in transfusion requirement or massive transfusion rates were observed.

Conclusion: The presence of TBI has no relevant impact on the applicability of the recently proposed BD-based classification of hypovolemic shock. This study underlines the role of BD as a relevant clinical indicator of hypovolaemic shock during the initial assessment in respect to haemostatic resuscitation and transfusion requirements.
\end{abstract}

Keywords: Trauma, Shock, Classification, Vital signs, Base deficit, Transfusion, Traumatic brain injury

\section{Background}

Uncontrolled haemorrhage is still responsible for the half of all trauma-related deaths within the first 48 hours after hospital admission [1-3]. This underlines the pivotal role of the early recognition and treatment of hypovolaemia in acute trauma care. The Advanced Trauma

\footnotetext{
* Correspondence: manuelmutschler@web.de

'Department of Trauma and Orthopedic Surgery, Cologne-Merheim Medical Center (CMMC), University of Witten/Herdecke, Ostmerheimer Str. 200, D-51109 Cologne, Germany

${ }^{2}$ Institute for Research in Operative Medicine (IFOM), University of Witten/ Herdecke, Ostmerheimer Str. 200, D-51109 Cologne, Germany

Full list of author information is available at the end of the article
}

Life Support (ATLS) proclaims for the initial evaluation of circulatory depletion four classes of hypovolemic shock based upon an estimated blood loss in percent and corresponding vital signs [4]. However, recent analyses on data of multiple injured patients derived from the TraumaRegister $\mathrm{DGU}^{\circ}$ and the TARN (Trauma Audit and Research Network) database indicated that the current ATLS classification of hypovolemic shock displays substantial deficits in the initial assessment of multiply injured trauma patients [5-8].

Based on these observations, we developed and validated a new classification of hypovolemic shock on the

\section{Biomed Central}


physiological shock marker base deficit (Table 1) [9]. The defined four strata of worsening BD indicated the acute presence of hypovolemic shock related to the need for haemostatic resuscitation, transfusion requirement, laboratory findings and outcomes [9]. This new classification of hypovolemic shock predicted transfusion requirements and mortality even more appropriately than the current ATLS classification of hypovolemic shock [9].

More than $40 \%$ of all trauma patients captured in the TraumaRegister $\mathrm{DGU}^{\circ}$ sustain a combination of injuries including severe traumatic brain injury (TBI) [8]. Together with hemorrhage, TBI is the leading cause of death in multiply injured trauma patients $[1-3,10]$ and the coincidence of TBI and hemorrhage has been associated with an even worse overall morbidity and mortality [11]. Several studies have shown that TBI may impair cardiovascular compensation to acute blood loss [12-16]. In detail, it has been demonstrated that the autonomic response to haemorrhage is disturbed in the presence of TBI and the physiological response to acute blood loss, like hypotension or the modification of vascular tone may be impaired or delayed $[14,15,17]$. Yuan and colleagues even demonstrated that TBI may suppress spontaneous hemodynamic recovery from hemorrhage and also impede the efficacy of fluid resuscitation [12,18]. Additionally, traditional vital signs like heart rate (HR), systolic blood pressure (SBP), shock index (SI) and Glasgow Coma Scale may be affected, indicating that current assessment strategies, like the ATLS classification of hypovolemic shock, have to be used with caution $[8,14,19]$.

Therefore, the aim of this study was to test the applicability of the novel BD-based classification of hypovolemic shock in the context of severe traumatic brain injury (TBI).

\section{Methods}

The TraumaRegister DGU ${ }^{\circledR}$ of the German Trauma Society The TraumaRegister $\mathrm{DGU}^{\circ}$, founded in 1993, is the official trauma registry of the German Trauma Society. Details of this registry have been published in extenso elsewhere $[5,8,9,20]$. To date, datasets from approximately $>450$ hospitals have been entered into the database. The TraumaRegister $\mathrm{DGU}^{\circ}$ captures all severe trauma patients, who are either admitted to the hospital via the emergency department (ED) with subsequent admission to an intensive care unit (ICU)/intermediate care unit (IMC) or reach the hospital with vital signs and die prior to ICU/IMC admission. The TraumaRegister $\mathrm{DGU}^{\circ}$ is approved by the review board of the German Trauma Society (DGU) and is in compliance with the institutional requirements of its members. Furthermore, all data analyses have been approved by the review board of the "Sektion NIS" of the German Trauma Society.

\section{Data analyses}

Datasets of multiple injured patients entered into the TraumaRegister $\mathrm{DGU}^{\circ}$ between 2002 and 2011 were analyzed. Inclusion criteria were age $\geq 16$ years, primary admission, and complete datasets for base deficit upon admission blood gas analysis in the emergency department. Severe traumatic brain injury was defined by an $\mathrm{AIS}_{\text {head }} \geq 3$ (abbreviated injury scale) as previously described [21-23]. Based on these criteria, 10,201 patients with severe TBI could be identified and were classified into four strata of worsening BD according to the recently proposed classification of hypovolemic shock (Table 1) [9]. Assessments included demographics, injury patterns and vital signs as present upon ED arrival. Additionally, therapeutic interventions such as administration of blood products, intravenous fluids and vasopressors were analyzed. The assessment of mortality was performed by analyzing the overall in-hospital mortality. Massive transfusion (MT) was defined by the administration of $\geq 10$ blood products between ED arrival and ICU admission. Coagulopathy was defined by a Quick's value $\leq 70 \%$, which is equivalent to an international normalized ratio (INR) of approximately $1.3[22,24]$. For the evaluation of the applicability of the novel BD-based classification in the context of severe TBI, patients with an $\mathrm{AIS}_{\text {head }} \geq 3$ were classified according to their $\mathrm{BD}$ at $\mathrm{ED}$ admission and compared to both, an unselected cohort of all trauma patients derived from the TraumaRegister $\mathrm{DGU}^{\circ}$ as well as to patients without a significant TBI (no TBI). Subsequently, transfusion requirements within the different cohorts were assessed.

\section{Statistical methods}

Data are shown as mean \pm standard deviation (SD) for continuous variables or percentages (\%) for categorical variables. GCS is displayed as median and interquartile ranges (IQR). For continuous variables, normal distribution was excluded using the Shapiro-Wilk test. To detect differences between the four groups of worsening $\mathrm{BD}$ a

Table 1 The BD-based classification of hypovolemic shock [9]

\begin{tabular}{ccccc}
\hline & Class I & Class II & Class III & Class IV \\
\hline Shock & none to minimal & mild & moderate & severe \\
BD at admission $(\mathrm{mmol} / \mathrm{l})$ & $\leq 2$ & $>2.0$ to 6.0 & $>6.0$ to 10.0 & $>10.0$ \\
Need for blood products & watch & consider & act & Be prepared for massive transfusion
\end{tabular}

Abbreviations: $B D$ base deficit. 
Kruskal-Wallis test was performed. Categorical variables were analyzed accordingly with the Chi-square test. For all statistical analyses, a probability of less than 0.05 was considered to be statistically significant. All data were analyzed using IBM SPSS (IBM SPSS 19, Chicago, USA).

\section{Results}

Characteristics of the four classes of hypovolemic shock in TBI patients

A total of 23,496 patients from the TraumaRegister $\mathrm{DGU}^{\bullet}$ were identified for further analysis. Out of these, 10,201 (43.4\%) patients presented with severe TBI defined by an $\mathrm{AIS}_{\text {head }} \geq 3$. General demographics and trauma mechanism for the four classes of hypovolemic shock are shown in Table 2. Worsening of BD category was associated with an increased injury severity score (ISS $25.8 \pm 11.9$ in class I to $41.6 \pm 17.0$ in class IV). Through the classes I to IV, this was paralleled by an increased incidence of sepsis $(7.5 \%$ to $14.1 \%)$ and multiple organ failure (18\% to 44.4). Overall in-hospital mortality increased from $15.9 \%$ in class I patients to $61.4 \%$ in class IV patients (Table 3). No relevant tachycardia was observed in any group and a substantial hypotension was found in class IV patients only. Patients with a $\mathrm{BD}>10.0 \mathrm{mmol} / \mathrm{l}$ (class IV) were coagulopathic (Table 4) and presented with significantly decreased haemoglobin levels $(9.4 \pm 3.2 \mathrm{~g} / \mathrm{dl})$ and platelet counts $(177 \pm 93 \mathrm{tsd} / \mu \mathrm{l})$ compared to class I patients (haemoglobin $12.6 \pm 2.3 \mathrm{~g} / \mathrm{dl}$; platelet counts $208 \pm 72 \mathrm{tsd} / \mu \mathrm{l})$.

Fluid resuscitation and transfusion requirement in correlation to increasing $\mathrm{BD}$ category are demonstrated in Table 5. Patients of class I received $1.5 \pm 6$ blood units, whereas class IV patients received $15.1 \pm 22$ blood units until ICU admission. The average transfusion ratio between packed red blood cells (pRBC's) and fresh frozen plasma (FFP's) was almost 1:1 within all groups. Likewise, observed and predicted transfusion requirements were concordant as the number of blood products transfused paralleled increased TASH (Trauma-Associated Severe Hemorrhage) scores.

Comparison of transfusion requirement between multiply injured patients with TBI and all trauma patients classified according to the BD-based classification of hypovolemic shock

In multiply injured patients with TBI, an increase in BD category was associated with a progressively increasing transfusion requirement (Figure 1). The percentage of patients who received $\geq 1$ blood unit during early ED resuscitation increased from $14 \%$ in class I to $64 \%$ in class IV (Figure 1A), while simultaneously massive transfusion rates increased stepwise from $5 \%$ in class I to $42 \%$ in

Table 2 Patients classified by BD (classes I to IV): demographics, injury mechanism and severities as well as outcome parameters

\begin{tabular}{|c|c|c|c|c|}
\hline & $\begin{array}{c}\text { Class I } \\
\mathrm{BD} \leq 2.0 \text { (none to minimal) }\end{array}$ & $\begin{array}{c}\text { Class II } \\
\text { BD }>2.0 \text { to } 6.0 \text { (mild) }\end{array}$ & $\begin{array}{c}\text { Class III } \\
\text { BD }>6.0 \text { to } 10.0 \text { (moderate) }\end{array}$ & $\begin{array}{c}\text { Class IV } \\
\text { BD }>10.0 \text { (severe) }\end{array}$ \\
\hline \multicolumn{5}{|l|}{ Demographics } \\
\hline n (total, \%) & $4369(42.8)$ & $3658(35.9)$ & $1404(13.8)$ & $770(7.5)$ \\
\hline Male (n, \%) & $3211(73.9)$ & $2636(72.6)$ & $982(70.5)$ & $523(68.2)$ \\
\hline Age (years; mean $\pm S D$ ) & $50.9(21.4)$ & $46.4(21)$ & $45.6(20.6)$ & $46.2(20.3)$ \\
\hline Blunt trauma $(n, \%)$ & $4121(97.3)$ & $3467(96.8)$ & $1332(96.2)$ & $703(93.1)$ \\
\hline \multicolumn{5}{|l|}{ Injury severity } \\
\hline ISS (points; mean \pm SD) & $25.8(11.9)$ & $30.2(13.6)$ & $35.2(15.9)$ & $41.6(17.0)$ \\
\hline AlS Thorax $\geq 3$ points $(n ; \%)$ & $1476(33.8)$ & $1642(44.9)$ & $742(52.8)$ & $486(63.1)$ \\
\hline AIS Abdomen $\geq 3$ points ( $n$; \%) & $236(5.4)$ & $395(10.8)$ & $270(19.2)$ & $19.9(25.8)$ \\
\hline AIS Pelvis/Extremities $\geq 3$ points ( $n$; \%) & $650(14.9)$ & $892(24.4)$ & $469(33.4)$ & $305(39.6)$ \\
\hline \multicolumn{5}{|l|}{ Outcome } \\
\hline Mortality (n; \%) & $696(15.9)$ & $805(22)$ & $502(35.8)$ & $473(61.4)$ \\
\hline Hospital LOS (days; mean \pm SD) & $18.1(17.8)$ & $21.7(25)$ & $20.8(24.8)$ & $16(29.1)$ \\
\hline ICU (days; mean \pm SD) & $10.8(12.2)$ & $13.5(13.8)$ & $14(15.9)$ & $11.1(16.8)$ \\
\hline Ventilator days (days; mean \pm SD) & $7.3(10.4)$ & $9.7(11.8)$ & $10.5(13.1)$ & $9.1(14.4)$ \\
\hline MOF $(n ; \%)$ & $694(18)$ & $876(26.8)$ & 389 (32.6) & $256(44.4)$ \\
\hline Sepsis (n, \%) & 296 (7.5) & $428(12.5)$ & 194 (15.8) & $83(14.1)$ \\
\hline
\end{tabular}

( $\mathrm{n}=10,201 ; \mathrm{p}<0.001$ for all parameters).

Abbreviations: ISS injury severity score, AIS abbreviated injury scale, LOS length of stay, ICU intensive care unit, MOF multiple organ failure. 
Table 3 Patients classified by BD (classes I to IV): traditional vital signs as presented at ED admission and at scene

\begin{tabular}{|c|c|c|c|c|}
\hline & $\begin{array}{c}\text { Class I } \\
\mathrm{BD} \leq \mathbf{2 . 0} \text { (none to minimal) }\end{array}$ & $\begin{array}{c}\text { Class II } \\
\text { BD }>2.0 \text { to } 6.0 \text { (mild) }\end{array}$ & $\begin{array}{c}\text { Class III } \\
\mathrm{BD}>6.0 \text { to } 10.0 \text { (moderate) }\end{array}$ & $\begin{array}{c}\text { Class IV } \\
\text { BD }>10.0 \text { (severe) }\end{array}$ \\
\hline \multicolumn{5}{|l|}{ Vital signs } \\
\hline $\mathrm{SBP}$ at ED $(\mathrm{mmHg} ;$ mean $\pm \mathrm{SD})$ & $132.3(28.6)$ & $124.3(30)$ & $113.2(32.4)$ & $95.7(40.9)$ \\
\hline $\mathrm{HR}$ at ED (beats/min; mean $\pm \mathrm{SD}$ ) & $84.3(18.4)$ & $88.7(21.6)$ & $95.3(23.4)$ & $96.5(32.9)$ \\
\hline GCS at ED (points; median, IQR) & $3(3-14)$ & $3(3-8)$ & $3(3-3)$ & $3(3-3)$ \\
\hline Intubation rate [pre-hospital] (n; \%) & $2306(54.5)$ & $2563(71.9)$ & $1116(81.4)$ & $674(89.2)$ \\
\hline
\end{tabular}

( $\mathrm{n}=10,201 ; \mathrm{p}<0.001$ for all parameters).

Abbreviations: SBP systolic blood pressure, HR heart rate, GCS Glasgow coma scale, ED Emergency Department.

class IV (Figure 1B). However, substantial and clinical relevant differences between patients who sustained TBI and the general trauma population were not observed within the four classes of hypovolemic shock based on BD. Similar results were seen when multiply injured patients with TBI were compared to a cohort of severely injured patients without TBI (Figure 1A and B). Only in group IV, patients without TBI had a slightly higher overall transfusion requirement. However, the clinical relevance of this finding remains questionable.

\section{Discussion}

The aim of this study was to test the applicability of the recently proposed classification of hypovolemic shock based on BD in multiple injured patients who have sustained severe traumatic brain injury.

Previous studies have demonstrated that base deficit detects the presence of hypovolemic shock and correlates with the need for haemostatic resuscitation, transfusion requirements, laboratory findings as well as mortality rates. In times of point-of-care testing, BD is available within minutes after ED admission [25]. Recent research provides evidence that the assessment of BD is a more useful approach to quantify the extent of hypovolemic shock than the estimation of blood loss, the extent of volume resuscitation or traditional vital signs such as HR and SBP [9,26-29] and may help to distinguish major from minor trauma [30]. The four classes of hypovolemic shock based on BD has been compared and validated against the ATLS classification of hypovolaemic shock. ATLS serves as a standard protocol for the initial assessment and treatment of severely injured trauma patients and has been widely implemented over the past decades. In this analysis, the BD-based classification has been shown to predict transfusion requirements and mortality more appropriately than the current ATLS classification of hypovolemic shock [9].

The present study focused on TBI patients with an $\mathrm{AIS}_{\text {head }} \geq 3$. Within this group of patients, worsening of $\mathrm{BD}$ category was associated with an increased injury severity and mortality, which is in accordance with several previous analyses [9,31-34] and has been also observed in pediatric and elderly trauma populations [35-38]. As expected, mortality rates across the four classes of hypovolemic shock were higher in multiple injured patients with TBI. In particular, $15.9 \%$ of class I and $22 \%$ of class II patients died within hospital stay and therefore nearly doubled mortality compared to our previous analysis on a general trauma population [9]. These findings are substantiated by Tremblay and colleagues who demonstrated that mortality increases with successive increase in base deficit but is also highly dependent on injury pattern. In TBI patients, mortality was markedly higher at a given $\mathrm{BD}$ than in patients suffering from stab wounds or lacerations [39]. Furthermore, in young trauma patients without TBI, a $25 \%$ mortality rate was observed at a BD

Table 4 Patients classified by BD (classes I to IV): laboratory findings

\begin{tabular}{|c|c|c|c|c|}
\hline & $\begin{array}{c}\text { Class I } \\
\mathrm{BD} \leq 2.0 \text { (none to minimal) }\end{array}$ & $\begin{array}{c}\text { Class II } \\
\text { BD }>2.0 \text { to } 6.0 \text { (mild) }\end{array}$ & $\begin{array}{c}\text { Class III } \\
\text { BD }>6.0 \text { to } 10.0 \text { (moderate) }\end{array}$ & $\begin{array}{c}\text { Class IV } \\
\text { BD }>10.0 \text { (severe) }\end{array}$ \\
\hline \multicolumn{5}{|l|}{ Laboratory findings } \\
\hline Haemoglobin ( $\mathrm{g} / \mathrm{dl}$; mean $\pm \mathrm{SD})$ & $12.6(2.3)$ & $11.8(2.5)$ & $10.7(2.9)$ & $9.4(3.2)$ \\
\hline Thrombocytes (tsd/ $\mu$ l; mean \pm SD) & $208(72)$ & $204(70)$ & $188(73)$ & $177(93)$ \\
\hline Quick's value (\%; mean \pm SD) & $84(20.9)$ & $77.8(22.8)$ & $68.2(25.0)$ & $54.7(26.6)$ \\
\hline $\mathrm{aPTT}$ (seconds; mean $\pm \mathrm{SD}$ ) & $30.7(11)$ & $33.9(16.3)$ & $41.9(26.6)$ & $61.8(42.8)$ \\
\hline
\end{tabular}


Table 5 Patients classified by BD (classes I to IV): haemostatic and fluid resuscitation

\begin{tabular}{|c|c|c|c|c|}
\hline & $\begin{array}{c}\text { Class I } \\
\mathrm{BD} \leq 2.0 \text { (none to minimal) }\end{array}$ & $\begin{array}{c}\text { Class II } \\
\text { BD }>2.0 \text { to } 6.0 \text { (mild) }\end{array}$ & $\begin{array}{c}\text { Class III } \\
\text { BD }>6.0 \text { to } 10.0 \text { (moderate) }\end{array}$ & $\begin{array}{c}\text { Class IV } \\
\text { BD }>10.0 \text { (severe) }\end{array}$ \\
\hline \multicolumn{5}{|l|}{ Transfusion requirements } \\
\hline All blood products/units ( $n$; mean \pm SD) & $1.5(6)$ & $4.2(11.5)$ & $9.4(17.5)$ & $15.1(22)$ \\
\hline pRBC transfusions/units ( $n$; mean \pm SD) & $1.1(3.4)$ & $2.6(5.8)$ & $5(8.4)$ & $8.1(10.9)$ \\
\hline FFP transfusions/units ( $n$; mean $\pm S D$ ) & $0.8(3.1)$ & $2.3(11.6)$ & $4.1(7.4)$ & $6.2(10)$ \\
\hline TC transfusion/units ( $\mathrm{n}$; mean $\pm \mathrm{SD}$ ) & $0.1(0.5)$ & $0.3(1.1)$ & $0.6(1.8)$ & $0.9(1.8)$ \\
\hline TASH Score (points; mean \pm SD) & $3.1(3.1)$ & $5.6(4.0)$ & $10.0(5.0)$ & $13.5(5.3)$ \\
\hline IV fliuds at ED (ml; mean \pm SD) & $1498(1531)$ & $2143(2075)$ & $2573(2404)$ & $2964(2564)$ \\
\hline Vasopressors at ED (n; \%) & $888(21.9)$ & $1233(36.1)$ & $690(52.3)$ & $549(75.8)$ \\
\hline
\end{tabular}

( $\mathrm{n}=10,201 ; \mathrm{p}<0.001$ for all parameters).

Abbreviations: $p R B C$ packed red blood cells, FFP fresh frozen plasma, TC thrombocyte concentrate, TASH Trauma-associated severe hemorrhage score, i.v. intravenous, ED Emergency Department.

level of $15 \mathrm{mmol} / \mathrm{l}$. In contrast, TBI patients showed same mortality rates already at a $\mathrm{BD}$ level of $8 \mathrm{mmol} / \mathrm{l}[33]$.

In the present study, increasing $\mathrm{BD}$ was associated with signs of hemodynamical instability and laboratory alterations such as drops in hemoglobin levels and platelet counts. Approximately one out of four patients in class III and IV presented coagulopathic at ED arrival which is in accordance to a previous analysis on isolated traumatic brain injuries by Wafaisade and colleagues [22]. Furthermore, BD correlated with an increasing overall amount of transfused blood units and with an increasing risk of ongoing hemorrhage as reflected by increasing TASH (trauma-associated severe hemorrhage) score values. These observations are supported by several studies demonstrating an association between increasing $\mathrm{BD}$ and the increased need for blood product transfusions as well as increasing amounts of i.v. fluids $[9,31,32,39]$.

In order to further assess the applicability of the BDbased classification of hypovolemic shock in the context of severe TBI, multiple injured patients who sustained also brain injury were compared to a cohort of all trauma patients. As there has been no gold standard introduced yet to assess hypovolaemic shock including blood loss in trauma which triggers therapeutic measures and interventions, the authors have decided to analyze and compare for transfusion requirements as a well-established surrogate for hypovolaemia. Both, the percentage of patients who received $\geq 1$ blood product as well as the percentage of patients who received massive transfusions were increasing throughout the groups I to IV. However, a relevant difference between both patient cohorts was not observed at all. In a second step, severely injured patients with TBI were also compared to a cohort of multiply injured trauma patients without any significant TBI. Only in group IV, a slight difference in transfusion requirements between both groups was observed. However, the clinical relevance of this finding remains questionable. These results are substantiated by an analysis on 131 patients with isolated head injury, demonstrating that TBI does neither alter BD levels nor reliably predicts the presence of TBI [23]. Therefore, the authors concluded that in patients with isolated head injury an increase of $\mathrm{BD}$ should lead to a
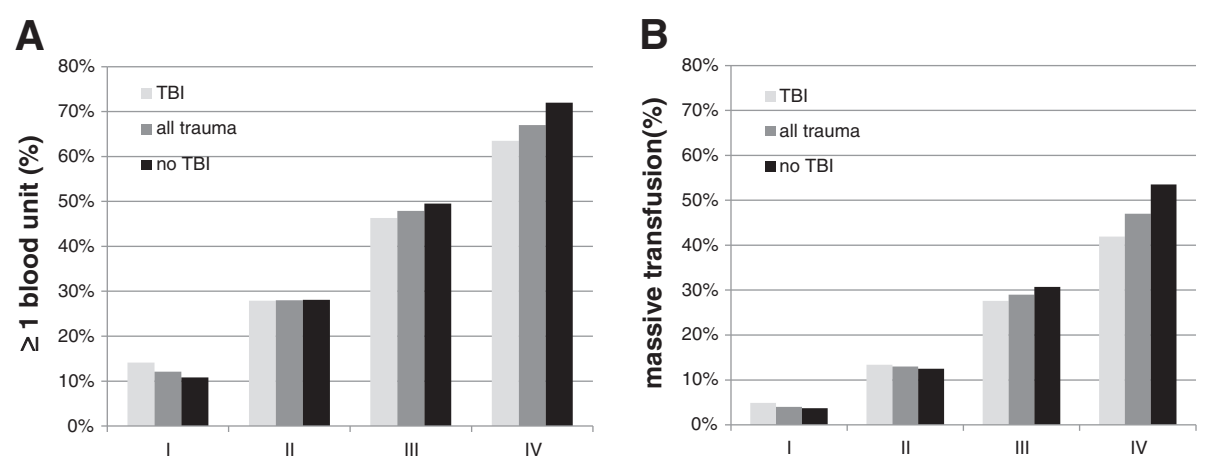

Figure 1 Transfusion requirements in multiply injured patients with $\mathrm{TBI}$, all trauma patients and multiply injured trauma patients without TBI. A) Percent of patients with $\geq 1$ blood product. $(n=23,496)$; B) Percent of patients with massive transfusion ( $\geq 10$ blood units until ICU admission). ( $n=23,496)$. Abbreviations: TBI: traumatic brain injury. 
careful assessment of extracranial injuries as the underlying reason for hypoperfusion and hence the raise in $\mathrm{BD}$.

Some limitations of the present study have to be acknowledged. First, this analysis is a retrospective study of trauma registry data with all the shortcomings associated with such an analysis. Second, not every ED is equipped with point-of-care testing. Consequently, BD values may not be available within the first minutes after ED admission. Further prospective clinical trials should be conducted to assess the accuracy of the proposed classification of hypovolemic shock in the clinical setting. But in spite of these restrictions, we are confident that determination of base deficit, as proclaimed in the BD based classification of hypovolemic shock, is a useful clinical tool to early risk-stratify patients who are in a state of hypovolemic shock and in need for early blood product transfusions, also in patients who sustained traumatic brain injury.

\section{Conclusions}

Our recently proposed classification of hypovolemic shock based on admission base deficit has been tested for its applicability in a large cohort of multiple injured patients with accompanying TBI. Within the four classes of hypovolemic shock (class I to IV), no clinical relevant differences in transfusion requirement in multiple injured patients with TBI and all trauma patients was observed. Consequently, this study underlines the role of $\mathrm{BD}$ as a relevant clinical indicator of hypovolaemic shock during the initial assessment and as a guide for transfusion requirements also in patients with traumatic brain injury.

\section{Abbreviations \\ AIS: Abbreviated injury scale; ATLS: Advanced Trauma Life Support; BD: Base deficit; DGU: Deutsche Gesellschaft für Unfallchirurgie (German Trauma Society); ED: Emergency Department; FFP: Fresh frozen plasma; GCS: Glasgow coma scale; HR: Heart rate; ICU: Intensive care unit; INR: International normalized ratio; IQR: Interquartile ranges; ISS: Injury severity score; i.v.: Intravenous; LOS: Length of stay; MOF: Multiple organ failure; MT: Massive transfusion; PC: Platelet concentrate; POCT: Point of care testing; pRBC: Packed red blood cells; PT: Prothrombin time; SBP: Systolic blood pressure; TARN: Trauma Audit and Research Network; TASH: Trauma-associated severe hemorrhage score; TBI: Traumatic brain injury.}

\section{Competing interests}

The authors declare that they have no competing interests. This is an unfunded study.

\section{Authors' contributions}

MMutschler contributed to study design, acquisition of data, interpretation and recording of paper. UN and BB contributed to analysis and interpretation of data and revision of the article. TB, AW, CP and TP contributed to study design and revision of the article. MMaegele contributed to study conception and design, acquisition of data, analysis and interpretation of data, and revision of the article. All authors read and approved the final manuscript.

\section{The TraumaRegister DGU}

Committee of Emergency Medicine, Intensive Care and Trauma Management of the DGU (Sektion NIS).

\section{Author details}

'Department of Trauma and Orthopedic Surgery, Cologne-Merheim Medical Center (CMMC), University of Witten/Herdecke, Ostmerheimer Str. 200, D-51109 Cologne, Germany. ${ }^{2}$ Institute for Research in Operative Medicine (IFOM), University of Witten/Herdecke, Ostmerheimer Str. 200, D-51109 Cologne, Germany. ${ }^{3}$ Academy for Trauma Surgery, Straße des 17.Juni 106-108, D-10623 Berlin, Germany.

Received: 5 August 2013 Accepted: 23 April 2014

Published: 30 April 2014

\section{References}

1. Anderson ID, Woodford M, De Dombal FT, Irving M: Retrospective study of 1000 deaths from injury in England and Wales. Br Med J 1988, 296:1305-1308.

2. Evans JA, Van Wessem KJP, McDougall D, Lee KA, Lyons T, Balogh ZJ: Epidemiology of traumatic deaths: comprehensive population-based assessment. World J Surg 2010, 34:158-163.

3. Sauaia A, Moore FA, Moore EE, Moser KS, Brennan R, Read RA, Pons PT: Epidemiology of trauma deaths: a reassessment. J Trauma 1995 38:185-193.

4. Kortbeek JB, Al Turki S, Ali J, Antoine J, Bouillon B, Brasel K, Brenneman F, Brink PR, Brohi K, Burris D, Burton R, Chapleau W, Cioffi W, Collet E, Cooper A, Cortes J, Eskesen V, Fildes J, Gautam S, Gruen RL, Gross R, Hansen KS, Henny W, Hollands MJ, Hunt RC, Jover Navalon JM, Kaufmann CR, Knudson P, Koestner A, Kosir R, et al: Advanced trauma life support, 8th edition, the evidence for change. J Trauma 2008, 64:1638-1650.

5. Mutschler M, Nienaber U, Brockamp T, Wafaisade A, Wyen H, Peiniger S, Paffrath T, Bouillon B, Maegele M: A critical reappraisal of the ATLS classification of hypovolaemic shock: does it really reflect clinical reality? Resuscitation 2012, 84:309-313.

6. Guly HR, Bouamra O, Little R, Dark P, Coats T, Driscoll P, Lecky FE: Testing the validity of the ATLS classification of hypovolaemic shock. Resuscitation 2010, 81:1142-1147.

7. Guly HR, Bouamra O, Spiers M, Dark P, Coats T, Lecky FE: Vital signs and estimated blood loss in patients with major trauma: testing the validity of the ATLS classification of hypovolaemic shock. Resuscitation 2011, 82:556-559.

8. Mutschler M, Nienaber U, Munzberg M, Fabian T, Paffrath T, Wolfl C, Bouillon B, Maegele M: Assessment of hypovolaemic shock at scene: is the PHTLS classification of hypovolaemic shock really valid? Emerg Med J 2014, 31:35-40.

9. Mutschler M, Nienaber U, Brockamp T, Wafaisade A, Fabian T, Paffrath T, Bouillon B, Maegele M, Dgu: Renaissance of base deficit for the initial assessment of trauma patients: a base deficit-based classification for hypovolemic shock developed on data from 16,305 patients derived from the TraumaRegister DGU. Crit Care 2013, 17:R42.

10. Bruns J, Hauser WA: The epidemiology of traumatic brain injury: a review. Epilepsia 2003, 44(Suppl 1):2-10.

11. Jeremitsky E, Omert L, Dunham CM, Protetch J, Rodriguez A: Harbingers of poor outcome the day after severe brain injury: hypothermia, hypoxia, and hypoperfusion. J Trauma 2003, 54:312-319.

12. Yuan $X Q$, Wade $C E$, Clifford CB: Suppression by traumatic brain injury of spontaneous hemodynamic recovery from hemorrhagic shock in rats. J Neurosurg 1991, 75:408-414.

13. Yuan $X Q$, Wade CE: Influences of traumatic brain injury on the outcomes of delayed and repeated hemorrhages. Circ Shock 1991, 35:231-236.

14. Goldstein B, Toweill D, Lai S, Sonnenthal K, Kimberly B: Uncoupling of the autonomic and cardiovascular systems in acute brain injury. Am J Physiol 1998, 275:R1287-R1292.

15. McMahon CG, Kenny R, Bennett K, Kirkman E: Modification of acute cardiovascular homeostatic responses to hemorrhage following mild to moderate traumatic brain injury. Crit Care Med 2008, 36:216-224.

16. McMahon CG, Kenny R, Bennett K, Little R, Kirkman E: Effect of acute traumatic brain injury on baroreflex function. Shock 2011, 35:53-58.

17. Chen B, Mutschler M, Yuan Y, Neugebauer E, Huang Q, Maegele M: Superimposed traumatic brain injury modulates vasomotor responses in third-order vessels after hemorrhagic shock. Scand J Trauma Resusc Emerg Med 2013, 21:77.

18. Yuan $X Q$, Wade CE: Traumatic brain injury attenuates the effectiveness of lactated Ringer's solution resuscitation of hemorrhagic shock in rats. Surg Gynecol Obstet 1992, 174:305-312. 
19. McMahon CG, Kenny R, Bennett K, Little R, Kirkman E: The effect of acute traumatic brain injury on the performance of shock index. J Trauma 2010, 69:1169-1175.

20. Scoring study committee of the German Society of Trauma Surgery: Trauma register of the German Society of Trauma Surgery. Unfallchirurgie 1994, 97:230-237.

21. Grote S, Böcker W, Mutschler W, Bouillon B, Lefering R: Diagnostic value of the Glasgow Coma Scale for traumatic brain injury in 18,002 patients with severe multiple injuries. J Neurotrauma 2011, 28:527-534.

22. Wafaisade A, Lefering $R$, Tjardes $T$, Wutzler $S$, Simanski C, Paffrath $T$, Fischer $P$, Bouillon B, Maegele M: Acute Coagulopathy in Isolated Blunt Traumatic Brain Injury. Neurocrit Care 2010, 12:211-219.

23. Zehtabchi S, Sinert R, Soghoian S, Liu Y, Carmody K, Shah L, Kumar M, Lucchesi M: Identifying traumatic brain injury in patients with isolated head trauma: are arterial lactate and base deficit as helpful as in polytrauma? Emerg Med J 2007, 24:333-335.

24. Wafaisade A, Wutzler S, Lefering R, Tjardes T, Banerjee M, Paffrath T, Bouillon $B$, Maegele M: Drivers of acute coagulopathy after severe trauma: a multivariate analysis of 1987 patients. Emerg Med J 2010, 27:934-939.

25. Mutschler M, Brockamp T, Wafaisade A, Lipensky A, Probst C, Bouillon B, Maegele M: "Time to TASH": how long does complete score calculation take to assess major trauma hemorrhage? Transfus Med 2013. doi:10.1111/tme.12089

26. Rixen D, Siegel JH: Bench-to-bedside review: oxygen debt and its metabolic correlates as quantifiers of the severity of hemorrhagic and post-traumatic shock. Crit Care 2005, 9:441-453.

27. Brasel KJ, Guse C, Gentilello LM, Nirula R: Heart rate: is it truly a vital sign? J Trauma 2007, 62:812-817.

28. Jansen TC, Van Bommel J, Mulder PG, Rommes JH, Schieveld SJM, Bakker J: The prognostic value of blood lactate levels relative to that of vital signs in the pre-hospital setting: a pilot study. Crit Care 2008, 12:R160.

29. Parks JK, Elliott AC, Gentilello LM, Shafi S: Systemic hypotension is a late marker of shock after trauma: a validation study of Advanced Trauma Life Support principles in a large national sample. Am J Surg 2006, 192:727-731.

30. Paladino L, Sinert R, Wallace D, Anderson T, Yadav K, Zehtabchi S: The utility of base deficit and arterial lactate in differentiating major from minor injury in trauma patients with normal vital signs. Resuscitation 2008, 77:363-368.

31. Davis JW, Parks SN, Kaups KL, Gladen HE, O'Donnell-Nicol S: Admission base deficit predicts transfusion requirements and risk of complications. J Trauma 1996, 41:769-774.

32. Rixen $D$, Raum $M$, Bouillon $B$, Lefering $R$, Neugebauer E: Base deficit development and its prognostic significance in posttrauma critical illness: an analysis by the trauma registry of the Deutsche Gesellschaft für unfallchirurgie. Shock 2001, 15:83-89.

33. Rutherford EJ, Morris JA, Reed GW, Hall KS: Base deficit stratifies mortality and determines therapy. J Trauma 1992, 33:417-423.

34. Siegel JH, Rivkind Al, Dalal S, Goodarzi S: Early physiologic predictors of injury severity and death in blunt multiple trauma. Arch Surg 1990, 125:498-508.

35. Jung J, Eo E, Ahn K, Cheon Y: Initial base deficit as predictors for mortality and transfusion requirement in the severe pediatric trauma except brain injury. Pediatr Emerg Care 2009, 25:579-581.

36. Kincaid EH, Chang MC, Letton RW, Chen JG, Meredith JW: Admission base deficit in pediatric trauma: a study using the National Trauma Data Bank. J Trauma 2001, 51:332-335.

37. Randolph LC, Takacs M, Davis KA: Resuscitation in the pediatric trauma population: admission base deficit remains an important prognostic indicator. J Trauma 2002, 53:838-842.

38. Davis JW, Kaups KL: Base deficit in the elderly: a marker of severe injury and death. J Trauma 1998, 45:873-877.

39. Tremblay LN, Feliciano DV, Rozycki GS: Assessment of initial base deficit as a predictor of outcome: mechanism of injury does make a difference. Am Surg 2002, 68:689-693.

doi:10.1186/1757-7241-22-28

Cite this article as: Mutschler et al: The impact of severe traumatic brain injury on a novel base deficit- based classification of hypovolemic shock. Scandinavian Journal of Trauma, Resuscitation and Emergency Medicine $201422: 28$ 